\title{
The Role of Social Self-Efficacy on Physical Activity: A Cross-Cultural Comparision
}

\author{
Serdar Alemdag \\ Correspondence: Serdar Alemdag, Karadeniz Technical University, Faculty of Sports Sciences, Trabzon, Turkey.
}

Received: February 6, 2018

doi:10.11114/jets.v6i5.2996
Accepted: March 6, $2018 \quad$ Online Published: March 26, 2018

URL: https://doi.org/10.11114/jets.v6i5.2996

\begin{abstract}
The purpose of this cross-cultural study exposes stages of change for exercise behavior (SCEB) in relation to perceived social self-efficacy (PSSE) between Turkey and England sport sciences students. The study group of the research consists of 168 (66 women and 102 men) students from Turkey and 217 (112 women and 105 men) students from England who completed a questionnaire package that included SCEB scale and The PSSE Scale. Descriptive statistics, t test, ANOVA, Chi-Square test were used as a statistical analysis. Results showed that the effect of PSSE on SCEB was significant between two counties and sport science students in Turkey have more PSSE than sport science students in England. Furthermore, it was found significant differences for the SCEB between Turkey and England and that sport science students living in England are significantly more physically active than sport science students living in Turkey. This result could explain that England has more sport neighborhood and facilities than Turkey.
\end{abstract}

Keywords: social self-efficacy, exercise behavior, physical activity, exercise, sport science, students

\section{Introduction}

Self-efficacy, a key part of social cognitive theory (Bandura, 1997), is one of the strongest psychosocial determinants of physical activity and exercise (Netz \& Raviv, 2004; Rogers, et al., 2005). The literature includes a great volume of research on psychosocial domains and self-efficacy (Alemdag \& et al 2016a; Alemdag, S. \& et al. 2016; Ozkara \& et al. 2016; Alemdag, C. \& et al. 2016b). Previous research has demonstrated that higher and lower levels of social self-efficacy are associated with shyness, depression instrumentality, expressiveness (Hermann \& Betz, 2004), emotional well-being (Bandura et al. 1996; Fabio, 2008), loneliness, social dissatisfaction (Galanaki \& Kalantzi, 1999), anxiety (Al-Darmaki, 2004; Xu, x.,et al. 2017), motivation (Bedel, 2016; Aydın, 2016) and stress (Matsushima \& Shiomi, 2003; Moeini, 2008). As social values constantly change and evolve, individuals feel constant concern about their economic status, academic achievements and social relations. In every society, individuals act according to their feelings, thoughts, and age; common problems such as emotional enthusiasm, easily established and broken relationships, and the desire to be dominant have today risen to prominence (Binbaşığlu, 1982; Başaran, 1998; Yörükoğlu, 1998). Researchers have focused on psychosocial work in order to minimize such problems in the society and to provide social change.

Self-efficacy, often used in social studies, refers to individuals' ability to organize their own perceptions and beliefs and to achieve the desired outcome and it includes individuals' perceived success, failure, and feedback (Bandura, 1997; Schunk \& Pajares, 2004). Research on self-efficacy has been examined from social, emotional and academic perspectives. This research focuses on social self-efficacy and participation in physical activity. social self-efficacy refers to an individual's beliefs about his or her abilities to establish social relations, cooperate with others, and manage conflicts among people (Bandura et al., 1999). Giunta (2010) notes that establishing positive relationships with others requires various social problem-solving skills. Becoming a successful individual in social life facilitates establishing good communication in everyday life. Additionally, the development of social skills contributes to the achievement of goals and a better evaluation of opportunities (Öztürk \& Şahin, 2007). In this regard, research on self-efficacy and physical activity has remarkably grown in recent years (Martin \& Kulinna, 2005; Motl, 2007; Gencay, 2009; Temple, 2009; Iskender \& Akin, 2010; Luszczynska et al., 2011; Cowan et al., 2012; Çetinkalp, 2012; Vurgun, 2015; XiaoXia, et al., 2016; Alemdag, 2018). Participation in physical activity brings people together and provides personal identity, social identity, and a sense of group membership; it also facilitates communication between people and communities without race, gender, culture and age discrimination (Yıldıran \& Yetim, 1996). Participation in physical activity has positive effects on self-respect (Chen et al., 2012; Joseph et al., 2014; Yiğitler, 2014), psychological well-being 
(Edwards, 2006; Garcia et al., 2012; Verner et al., 2017; Wiese et al., 2018), physical and mental health (Cho \& Cho, 2011; Park et al., 2017; Ostovarfar et al., 2018; Way et al., 2018); however, the number of people who do not participate in physical activity is quite high worldwide (World Health Organization, 2004). For example, Bauman (2009) collected data from about 53 thousand people across 20 countries and reported that New Zealand, Czech Republic, the USA, Canada and Australia are the countries where participation in physical activity is most prevalent, while the levels of physical activity are remarkably quite low in the remaining countries.

There are various scales measuring participation in physical activity (Craig et al., 2003; Wareham et al., 2003; Cleland et al., 2014). The stages of change for exercise behavior questionnaire is widely used and research results have shown that men have higher levels of participation in physical activity than women (Juniper et al., 2004; Prapavessis et al., 2004; Cengiz, 2007; Kanning, 2010; Langdon et al., 2017). Research on university students has reported that most university students are at pre-contemplation, contemplation and preparation stages, namely passive stages, of change for exercise behavior (Wakui et al., 2002; Cardinal et al., 2004; Juniper et al., 2004; Keating et al., 2005b; Cengiz, 2007). Individual or collective participation in physical activity has positive effects on social relations and individuals' self-development. A literature review indicated that there is a limited volume of cross-cultural research on participation in physical activity and social self-efficacy. Thus, research investigating participation in physical activity and social self-efficacy of sports science students studying in Turkey and the UK seems to be important to fill the gap in the literature.

\subsection{Purpose of Research}

The purpose of this cross-cultural research is to analyze the stages of change for exercise behavior (SCEB) and perceived social self-efficacy (PSSE) of sports science students studying in Turkey and the UK and to investigate whether social self-efficacy has an effect on exercise behavior.

\section{Method}

Participants: Participants were 168 (66 women and 102 men) sport sciences students from Turkey and 217 (112 women and $105 \mathrm{men}$ ) sport sciences students from England who completed a questionnaire package that included The Stages of Change for Exercise Behavior scale (SCEB) and The Perceived Social Self-Efficacy Scale (PSSE) for the 2015-2016 academic year.

Materials: Perceived Social self-efficacy Scale (PSSE); Smith and Betz (2000) define social self-efficacy as "an individual's confidence in his or her ability to engage in the social international task necessary to initiate and maintain interpersonal relationship. The scale of perceived social self-efficacy (PSSE) consists of 25 rationally derived item that measure the level of confidence in a variety of social situations.

Stages of Change for Exercise Behavior Scale (SCEB); Students' stages of change for exercise behavior were assessed using a measure with five stages (Marcus, et al., 1992): These stages are pre contemplation, contemplation, preparation, action and maintenance. The participants were required to select only one stage that best described their current exercise pattern. The participants whose responses classified them as being in the action and maintenance stages also reported the greatest weekly participation in physical activity. Those classified being in the Pre-contemplation and Contemplation stages were "non-exercisers."

Procedure and Statistical Analysis: This research used questionnaires as date collection method. The questionnaires were distributed after obtaining the necessary permit from universities and consent form from students. The participation in the survey was voluntary. Descriptive statistics, $t$ test, one-way ANOVA, Chi-Square test were used as an statistical analysis.

\section{Result}

The sample of the research consist of totally 385 sport sciences students. 168 of them from Turkey and 217 from England. In Turkey, 66 (39.2\%) women and 102 (60.8\%) man and in England, 112 (51.6\%) women and 105 (48.4\%) men who accepted the questionnaires.

Table 1. Chi-Square Test for The Stages of Change in Exercise Behavior Between Turkey and England

\begin{tabular}{llll}
\cline { 2 - 3 } & SCEB & TR (n / \%) & ENG (n / \%) \\
\cline { 2 - 4 } & Passive & $38(22.6)$ & $3(1.4)$ \\
Preparation & $36(21.4)$ & $11(5)$ \\
Active & $94(55.9)$ & $203(93.6)$ \\
\hline Total & $168(100)$ & $217(100)$ \\
\hline
\end{tabular}

$\chi^{2}=78.21, \mathrm{df}=2, \mathrm{p}=.00$

Presented in Table 1, sport sciences students from Turkey and England differ in the stages of change in exercise 
behavior. In Turkey, the distribution of the sample consisted of 168 persons and 38 (22.6\%) in the passive level, 36 (21.4\%) in preparation, 94 (55.9\%) in active level. In contrast, in England the distribution of the sample consisted of 217 persons and $3(1.4 \%)$ in the passive level, $11(5 \%)$ in preparation and $203(93.6 \%)$ in active level. The result show significant differences between the stages of change in exercise behavior of Turkish and English sport science students $\left(\mathrm{X}^{2}(2)=78.21, \mathrm{p}<.001\right)$

Table 2. t-Test results comparing Turkey and England on PSSE

\begin{tabular}{llllllll}
\hline & Country & $\mathrm{n}$ & Mean & SD & $\mathrm{t}$ & $\mathrm{df}$ & $\mathrm{p}$ \\
\hline \multirow{2}{*}{ PSSE } & TR & 168 & 3.84 & 0.6 & \multirow{2}{*}{8.58} & \multirow{2}{*}{383} & .00 \\
& ENG & 217 & 3.34 & 0.5 & & & \\
\hline
\end{tabular}

Table 2 shows that an independent sample t-test was conducted to compare students' Perceived Social Self-Efficacy (PSSE) between Turkey and England. As we see from Table 2, there was a significant difference in the scores for PSSE in Turkey $(\mathrm{M}=3.84, \mathrm{SD}=0.6)$ and England $(\mathrm{M}=3.34, \mathrm{SD}=0.5)$ conditions; $\mathrm{t}(385)=8.58, \mathrm{p}=.00$. These results suggest that Turkish sport science students have more PSSE than English sport science students.

Table 3a. Means and standard deviations on the measure of perceived social self-efficacy as a function of stages of change for exercise behavior among sports science students

\begin{tabular}{lrll}
\hline & & \multicolumn{2}{l}{ Perceived social self-efficacy } \\
\cline { 3 - 4 } SCEB & $n$ & $M$ & $S D$ \\
\hline Passive & 41 & 3.70 & 0.63 \\
Preparation47 & 3.69 & 0.63 \\
\multicolumn{2}{l}{ Active } & 2973.51 & 0.60 \\
\hline
\end{tabular}

Analysis of variance showed that the effect of perceived social self-efficacy on stages of change for exercise behavior was significant $F(2,382)=3.14, p<.05$. In other words, the overall perceived social self-efficacy of sports science students varies according to the stages of change in exercise behaviors. According to the results of the Tukey HSD test conducted to find the difference between the perceived social self-efficacy of the learners and related exercise behaviour change step of this difference, the social self-efficacy of students in the passive and preparatory stages of exercise behavior $(M=3.7, M=3.69)$ is higher than social self-efficacy $(M=3.51)$ of students in the active stages of exercise behavior $(\mathrm{M}=3.51)$.

Table 3b. One-way analysis of variance of perceived social self-efficacy by stages of change for exercise behavior

\begin{tabular}{|c|c|c|c|}
\hline & $d f S S$ & $M S F$ & $p$ \\
\hline$C^{\prime}$ & $\mathrm{s} 2 \quad 2.36$ & 1.183. & \\
\hline Within Groups & 382143. & 400.37 & \\
\hline Total & 384145 . & & \\
\hline
\end{tabular}

$* p<.05$.

\section{Discussion}

This cross-cultural research aimed to analyze the stages of change for exercise behavior (SCEB) and perceived social self-efficacy (PSSE) of sports science students studying in Turkey and the UK and to investigate whether social self-efficacy has an effect on exercise behavior. Given the lack in the literature of cross-cultural research on stages of change for exercise behavior and perceived social self-efficacy, this research designed to involve sports science students from Turkey and the UK is of importance in contributing to the literature. For the purpose of the research, SCEB- and PSSE-related data were collected from sports science students in Turkey and the UK and analyzed. The analysis results indicated a significant difference between exercise behaviors and perceived social self-efficacy of sports science students in Turkey and the UK. This result is consistent with the results of previous research on participation in physical activity and self-efficacy (Alemdag, 2013; Vurgun, 2015; Alemdag, 2017; Allami et al., 2017; Briki, 2018; Ciciurkaite et al., 2018; Wickman et al., 2018). This situation indicates that there is a valid structure between participation in physical activity and self-efficacy in national, international, and cross-cultural research.

According to the research results, there was a significant difference between exercise behaviors of sports science students studying in Turkey and the UK. English sport science students involved in this research tended to be more physically active than their Turkish counterparts. This result seems to stem from the abundance of areas suitable for sports culture and exercise in the UK. This result is consistent with Alemdağ's (2017) research. Santos et al. (2017) surveyed Mozambican and Portuguese young people and found that Mozambicans are less involved in physical activity than the Portuguese. They associated this result with the undesirable effect of urbanization in developing countries. Arvidsson et al. (2014) reported that Iraqi young people are less sufficiently physically active 
compared to the Swedes and the Iraqis also spend less time in physical activity.

Considering the data on perceived social self-efficacy, there was also a significant difference between sports science students studying in two countries. Accordingly, sports science students in Turkey had higher perceived social self-efficacy than those in the UK. Alemdağ et al. (2017) investigated Turkish and English university students' participation in physical activity and social self-efficacy and found that students' perceived social self-efficacy was significantly different. These results can be explained by the fact that Turkey is located in the temperate climate zone and Turkish people are often more social and friendly.

\section{Conclusion}

Promoting physical activity has become a public priority in developed countries worldwide. They needed to support the development of effective strategies and interventions that promote an active lifestyle and prevent a sedentary one. Turkey should also take necessary measures for increasing physical activity participation rates, and people should be encouraged. As a conclusion, conducting studies to increase PSSE may help to foster greater rates of physical activity participation.

\section{Acknowledgements}

The authors would like to thank The Scientific and Technological Research Council of Turkey (TUBITAK) for support this research and special thanks to Prof Nikos Ntoumanis, Dr. Maria Kavussanu and Dr. Ian Boardley for support on this manuscript.

\section{References}

Al-Darmaki, F. R. (2004). Counselor training, anxiety, and counseling self-efficacy: Implications for training psychology students from the United Arab Emirates University. Social Behavior and Personality: an International Journal, 32(5), 429-439. https://doi.org/10.2224/sbp.2004.32.5.429

Alemdağ, C., Alemdağ, S. \& Özkara, A. B. (2016b). Physical activity as a determinant of subjective happiness. Baltic Journal of Sport and Health Sciences, 103(4), 2-10.

Alemdağ, C., Kalkavan, A., Alemdağ, S., \& Özkara, A. B. (2016a). The Learning Styles of Student Athletes according to Alma Mater and Academic Achievement. International Journal of Science Culture and Sport, 4(17), 146-155. https://doi.org/10.14486/IntJSCS543

Alemdag, S. (2018). Participation in Physical Activity, Appearance Anxiety and Self-Efficacy Relation. (1st ed.) [In Turkish]. Gece Kitaplığı: Ankara.

Alemdağ, S., Alemdağ, C., \& Özkara, A. B. (2016). Social Appearance Anxiety of Fitness Participant. Baltic Journal of Sport and Health Sciences, 102(3), 2-7.

Alemdag, S., Alemdag, C., \& Ozkara, A. B. (2017). An Investigation of Physical Activity and Social Self-Efficacy of University Students: The Example of Turkey and England. Khazar Journal Of Humanitles And Social Sciences, Special issue, 135-146.

Allami, F. B., Fauzee, M. S. O., \& Sin, I. (2017). The Relationship between Physical Education Teacher's Self-efficacy and Job Satisfaction in Iraq Physical Education Colleges. International Journal of Innovative Research and Development, 6(8). https://doi.org/10.24940/ijird/2017/v6/i8/AUG17001

Arvidsson, D., Leijon, M., Sundquist, J., Sundquist, K., Lindblad, U., \& Bennet, L. (2014). Cross-cultural validation of a simple self-report instrument of physical activity in immigrants from the Middle East and native Swedes. Scandinavian Journal of Social Medicine, 42(3), 255-262. https://doi.org/10.1177/1403494813514143

Aydın, S. (2016). An Analysis of the Relationship between High School Students' Self-efficacy, Metacognitive Strategy Use and their Academic Motivation for Learn Biology. Journal of Education and Training Studies, 4(2), 53.

Bandura, A. (1997). Self-efficacy. In V. S. Ramachaudran (Ed.), Encyclopedia of human behavior (vol. 4, pp. 71-81). NewYork, NY: Academic Press Reprinted in H. Friedman [Ed.]. 1998. Encyclopedia of mental health. San Diego: Academic Press.

Bandura, A., Barbaranelli, C., Caprara, G. V., \& Pastorell1, C. (1996). Multifaceted impact of self-efficacy belief on academic functioning. Child development. 67, 1206-1222. https://doi.org/10.1111/j.1467-8624.1996.tb01791.x

Bandura, A., Pastorelli, C., Barbaranelli, C., \& Caprara, G. V. (1999). Self-efficacy pathways to childhood depression. Journal of Personality and Social Psychology, 76, 258. https://doi.org/10.1037/0022-3514.76.2.258

Başaran, I. E. (1998). Education psychology [In Turkish]. Ankara: M.E.B.

Bauman, A., Bull, F., Chey, T., Craig, C. L., Ainsworth, B. E., Sallıs, J. F., \& Pratt, M. (2009). The international prevalence study on physical activity: results from 20 countries. International Journal of Behavioral Nutrition and 
Physical. Activity, 6(1), 21. https://doi.org/10.1186/1479-5868-6-21

Bedel, E. F. (2016). Exploring Academic Motivation, Academic Self-efficacy and Attitudes toward Teaching in Pre service Early Childhood Education Teachers. Journal of education and training studies, 4(1), 142.

Binbaşıoglu, C. (1982). Education psychology (5th ed.) [In Turkish]. Ankara: Binbaşığlu.

Briki, W. (2018). Why do exercisers with a higher trait self-control experience higher subjective well-being? The mediating effects of amount of leisure-time physical activity, perceived goal progress, and self-efficacy. Personality and Individual Differences, 125, 62-67. https://doi.org/10.1016/j.paid.2017.12.020

Cardinal, B. J., Tuominen, K. J., \& Rintala, P. (2004). Cross-cultural comparison of American and finnish college students' exercise behavior using transtheoretical model constructs. Research Quarterly for Exercise and Sport, 75(1), 92-101. https://doi.org/10.1080/02701367.2004.10609137

Cengiz, C. (2007). Physical activity and exercise stages of change levels of Middle East Technical University students. Unpublished master thesis. Ankara, Turkey: Middle East Technical University

Cetinkalp, Z. K. (2012). Achievement goals and physical self-perceptions of adolescent athletes. Social Behavior and Personality: an International Journal, 40(3), 473-480. https://doi.org/10.2224/sbp.2012.40.3.473

Chen, W. I., Chen, C. Y., Lin, Y. H., \& Chen, T. T. (2012). Sport participation and self-esteem as mediated by perceived peer acceptance and sport self-concept in Taiwanese college students. Social Behavior and Personality: An International Journal, 40(4), 699-704. https://doi.org/10.2224/sbp.2012.40.4.699

Cho, M. H., \& Cho, B. J. (2011). A case study of physical activity levels and medical expenditure of the Korean middle aged. South African Journal for Research in Sport, Physical Education and Recreation, 33(2), 35-44. https://doi.org/10.4314/sajrs.v33i2.69687

Ciciurkaite, G., Tarasenko, Y., \& Schoenberg, N. (2018). Self-efficacy and Leisure-time Physical Activity among Rural Residents. Health Behavior and Policy Review, 5(1), 16-27. https://doi.org/10.14485/HBPR.5.1.2

Cleland, C. L., Hunter, R. F., Kee, F., Cupples, M. E., Sallis, J. F., \& Tully, M. A. (2014). Validity of the Global Physical Activity Questionnaire (GPAQ) in assessing levels and change in moderate-vigorous physical activity and sedentary behaviour. BMC public health, 14(1), 1255. https://doi.org/10.1186/1471-2458-14-1255

Cowan, J., Slogrove, C. L., \& Hoelson, C. N. (2012). Self-efficacy and social support of academy cricketers. South African Journal for Research in Sport, Physical Education and Recreation, 34(2), 27-39.

Craig, C. L., Marshall, A. L., Sjorstrom, M., Bauman, A. E., Booth, M. L., Ainsworth, B. E., \& OJA, P. (2003). International physical activity questionnaire: 12-country reliability and validity. Medicine and science in sports and exercise, 35(8), 1381-1395. https://doi.org/10.1249/01.MSS.0000078924.61453.FB

Di Giunta, L., Eisenberg, N., Kupfer, A., Steca, P., Tramontano, C., \& Caprara, G. V. (2010). Assessing perceived empathic and social self-efficacy across countries. European Journal of Psychological Assessment. https://doi.org/10.1027/1015-5759/a000012

Dinç, Z. (2011). Social self-efficacy of adolescents who participate in individual and team sports. Social Behavior and Personality: An International Journal, 39(10), 1417-1423. https://doi.org/10.2224/sbp.2011.39.10.1417

Edwards, S. (2006). Physical exercise and psychological well-being. South African journal of psychology, 36(2), 357-373. https://doi.org/10.1177/008124630603600209

Fabio, A. D., \& Palazzeschi, L. (2008). Emotional intelligence and self-efficacy in a sample of Italian high school teachers. Social Behavior and Personality: An International Journal, 36(3), 315-326. https://doi.org/10.2224/sbp.2008.36.3.315

Galanaki, E. P., \& Kalantzi-Azizi, A. (1999). Loneliness and social dissatisfaction: its relation with children self-efficacy for peer enteraction. Child Study Journal 29, 1-22. https://doi.org/10.1177/0143034308090061

Garcia, D., Archer, T., Moradi, S., \& Andersson-Arntén, A. C. (2012). Exercise frequency, high activation positive affect, and psychological well-being: beyond age, gender, and occupation. Psychology, 3(04), 328. https://doi.org/10.4236/psych.2012.34047

Gencay, O. A. (2009). Validation of the physical education teachers' physical activity self-efficacy scale with a Turkish sample. Social Behavior and Personality: an international journal, 37(2), 223-230. https://doi.org/10.2224/sbp.2009.37.2.223

Hermann, K. S., \& Betz, N. E. (2004). Path models of the relationship of instrumentality and expressiveness to social self-efficacy, shyness and depressive symptoms. Sex Roles, 
51(1/2).https://doi.org/10.1023/B:SERS.0000032309.71973.14

Iskender, M., \& Akin, A. (2010). Social self-efficacy, academic locus of control and internet addiction. Computers and Education 54, 1101-1106. https://doi.org/10.1016/j.compedu.2009.10.014

Joseph, R. P., Royse, K. E., Benitez, T. J., \& Pekmezi, D. W. (2014). Physical activity and quality of life among university students: exploring self-efficacy, self-esteem, and affect as potential mediators. Quality of life research, 23(2), 659-667. https://doi.org/10.1007/s11136-013-0492-8

Juniper, K. C., Oman, R. F., Hamm, R. M., \& Kerby, S. S. (2004). The relationships among constructs in the health belief model and the trans theoretical model among African- American college women for physical activity. American Journal of Health Promotion, 18 (5), 354-357. https://doi.org/10.4278/0890-1171-18.5.354

Kanning, M. (2010). Physically active patients with coronary artery disease: a longitudinal investigation of the processes of exercise behaviour change. British journal of health psychology, 15(3), 583-597. https://doi.org/10.1348/135910709X477476

Keating, X. D., Guan, J., Huang, Y., Deng, M., Wu, Y., \& Qu, S. (2005b). Cross-cultural validation of stages of exercise change scale among Chinese college students. European Physical Education Review, 11(1), 71-83. https://doi.org/10.1177/1356336X05049825

Langdon, J., Johnson, C., \& Melton, B. (2017). Factors contributing to the uptake and maintenance of regular exercise behaviour in emerging adults. Health Education Journal, 76(2), 182-193.

https://doi.org/10.1177/0017896916654934

Luszczynska, A., Schwarzer, R., Lippike, S., \& Mazurkiewicz, M. (2011). Self-Efficacy as a moderator of the planning-behaviour relationship interventions designed to promote physical activity. Psychology and Health, 26(2), 151-166. https://doi.org/10.1080/08870446.2011.531571

Martin, J. J., \& Kulinna, P. H. (2005). A social cognitive perspective of physical activity related behavior in physical education. Journal of Teaching in Physical Education, 24(3), 265-281. https://doi.org/10.1123/jtpe.24.3.265

Matsushima, R., \& Shiomi, K. (2003). Social self-efficacy and interpersonal stress in adolescence. Social Behavior and Personality: An International Journal, 31(4), 323-332. https://doi.org/10.2224/sbp.2003.31.4.323

Moeini, B., Shafii, F., Hidarnia, A., Babaii, G. R., Birashk, B., \& Allahverdipour, H. (2008). Perceived stress, self-efficacy and its relations to psychological well-being status in Iranian male high school students. Social Behavior and Personality: An International Journal, 36(2), 257-266. https://doi.org/10.2224/sbp.2008.36.2.257

Motl, R. W. (2007). Theoretical models for understanding physical activity behavior among children and adolescents-social cognitive theory and self-determination theory. Journal of Teaching in Physical Education, 26(4), 350-357. https://doi.org/10.1123/jtpe.26.4.350

Netz, Y., \& Raviv, S. (2004). Age differences in motivational orientation toward physical activity: An application of social-cognitive theory. Journal of Psychology. 138(1), 35-48. https://doi.org/10.3200/JRLP.138.1.35-48

Ostovarfar, J., Kaveh, M. H., Ghahremani, L., Radmanesh, S., Fararooei, M., \& Maghsoudi, A. (2018). Does Physical Activity Could Moderate Perceived Wellness of Health Providers?. Shiraz E-Medical Journal, 19(1).

Ozkara A. B., Kalkavan A., Alemdağ S., \& Alemdağ C. (2016). The Role of Physical Activity In Psychological Resilience. Baltic Journal of Sport \& Health Sciences, 102(3), 24-29.

Ozturk, F., \& Sahin, Ş. K. (2007). Comparison of the Social Self Efficacy Results of 9-13 Age Groups Individuals Who Do Sports And Don't Do (Bursa Sample). Elementary Education Online, 6(3), 468-479.

Park, S., Thøgersen-Ntoumani, C., Ntoumanis, N., Stenling, A., Fenton, S. A., \& Veldhuijzen Van Zanten, J. J. (2017). Profiles of Physical Function, Physical Activity, and Sedentary Behavior and their Associations with Mental Health in Residents of Assisted Living Facilities. Applied Psychology: Health and Well-Being, 9(1), 60-80. https://doi.org/10.1111/aphw.12085

Prapavessis, H., Maddison, R., \& Brading, F. (2004). Understanding exercise behavior among New Zealand adolescents: a test of the trans theoretical model. Journal of Adolescent Health, 35(2), 17-27.

Rogers, L. Q., Shah, P., Dunnington, G., Greive, A., Shanmugham, A., Dawson, B., \& Courneya, K. S. (2005). Social cognitive theory and physical activity during breast cancer treatment. In Oncology Nursing Forum, 32(4), 807-815. https://doi.org/10.1188/05.ONF.807-815

Santos, F. K. D., Prista, A., Gomes, T. N., Souza, M., Tchonga, F., Damasceno, A., \& Maia, J. (2017). A cross-cultural study of physical activity and sedentariness in youth from Mozambique and Portugal. Motriz: Revista de Educação 
Física, 23(SPE2).

Schunk, D. H., \& Pajares, F. (2004). Self-efficacy in education revisited: Empirical and applied evidence. InD.M.McInerney \& S. Van Etten (Eds.), Big theories revisited, 115-138. Greenwich, CT: Information Age.

Temple, V. A. (2009). Factors associated with high levels of physical activity among adults with intellectual disability. International Journal of Rehabilitation Research, 32(1), 89-92. https://doi.org/10.1097/MRR.0b013e328307f5a0

Verner-Filion, J., Vallerand, R. J., Amiot, C. E., \& Mocanu, I. (2017). The two roads from passion to sport performance and psychological well-being: The mediating role of need satisfaction, deliberate practice, and achievement goals. Psychology of Sport and Exercise, 30, 19-29. https://doi.org/10.1016/j.psychsport.2017.01.009

Vurgun, N. (2015). Effects of regular aerobic exercise on physical characteristics, body image satisfaction and self-efficacy of middle-aged women. South African Journal for Research in Sport, Physical Education and Recreation, 37(1), 151-163.

Wareham, N. J., Jakes, R. W., Rennie, K. L., Schuit, J., Mitchell, J., Hennings, S., \& Day, N. E. (2003). Validity and repeatability of a simple index derived from the short physical activity questionnaire used in the European Prospective Investigation into Cancer and Nutrition (EPIC) study. Public Health Nutrition, 6(4), 407-413. https://doi.org/10.1079/PHN2002439

Way, K., Kannis-Dymand, L., Lastella, M., \& Lovell, G. P. (2018). Mental health practitioners' reported barriers to prescription of exercise for mental health consumers. Mental Health and Physical Activity. https://doi.org/10.1016/j.mhpa.2018.01.001

Wickman, K., Nordlund, M., \& Holm, C. (2018). The relationship between physical activity and self-efficacy in children with disabilities. Sport in Society, 21(1), 50-63. https://doi.org/10.1080/17430437.2016.1225925

Wiese, C. W., Kuykendall, L., \& Tay, L. (2018). Get active? A meta-analysis of leisure-time physical activity and subjective well-being. The Journal of Positive Psychology, 13(1), 57-66. https://doi.org/10.1080/17439760.2017.1374436

World Health Organization (2004). Global Strategy On Diet, Physical Activity and Health.

Xiaoxia, S., Ping, X., Mcbride, R. E., Jiling, L., \& Thornton, M. A. (2016). At-risk boys' social self-efficacy and physical activity self-efficacy in a summer sports camp. Journal of Teaching in Physical Education, 35(2), 159-168. https://doi.org/10.1123/jtpe.2014-0176

Xu, X., Lou, L., Wang, L., \& Pang, W. (2017). Adolescents' perceived parental psychological control and test anxiety: Mediating role of academic self-efficacy. Social Behavior and Personality: an international journal, 45(9), 1573-1583. https://doi.org/10.2224/sbp.6754

Yiğiter, K. (2014). The effects of participation in regular exercise on self-esteem and hopelessness of female university students. Social Behavior. https://doi.org/10.2224/sbp.2014.42.8.1233

Yıldıran, I., \& Yetım, A. A. (1996). Ortaöğretimde beden eğitimi ve spor dersinin öncelikli amaçları üzerine bir araştırma. Gazi Üniversitesi, Beden Eğitimi ve Spor Bilimleri Dergisi, 1(3).

Yorukoglu, A. (1998). Children's mental health (23rd ed.) [In Turkish]. Istanbul: Özgür.

\section{Copyrights}

Copyright for this article is retained by the author(s), with first publication rights granted to the journal.

This is an open-access article distributed under the terms and conditions of the Creative Commons Attribution license which permits unrestricted use, distribution, and reproduction in any medium, provided the original work is properly cited. 